\title{
An Evaluation of the Water Absorption and Density Properties of Expanded Polystyrene Sanded Concrete
}

\author{
Johnson C. Abah ${ }^{1}$, Emmanuel E. Ndububa², Elias O. Ikpe ${ }^{2}$ \\ ${ }^{1}$ Department of Civil Engineering, Federal Polytechnic, Kaura-Namoda, Nigeria \\ ${ }^{2}$ Department of Civil Engineering, University of Abuja, Abuja, Nigeria \\ Email: *ajonye2006@gmail.com
}

How to cite this paper: Abah, J.C., Ndububa, E.E. and Ikpe, E.O. (2018) An Evaluation of the Water Absorption and Density Properties of Expanded Polystyrene Sanded Concrete. Open Journal of Civil Engineering, 8, 524-532.

https://doi.org/10.4236/ojce.2018.84037

Received: June 19, 2018

Accepted: December 22, 2018

Published: December 25, 2018

Copyright ( 92018 by authors and Scientific Research Publishing Inc. This work is licensed under the Creative Commons Attribution International License (CC BY 4.0).

http://creativecommons.org/licenses/by/4.0/

\begin{abstract}
In this paper, the evaluation of the mechanical and hygro-thermal properties of expanded polystyrene-sanded lightweight concrete (EPSLC) was examined. Evaluated are the mechanical properties in terms of density; and the hygro-thermal property using water absorption (capillary absorption and total immersion) as measures. The research used 30\% volume of EPS to replace natural coarse aggregate to produce a lightweight concrete, which is expected to be economical, serviceable and meet the required standards for lightweight concretes. The concrete bulk and oven dry densities were obtained as $1789 \mathrm{KN} / \mathrm{m}^{3}$ and $1674 \mathrm{~kg} / \mathrm{m}^{3}$ respectively while the total water and capillary water absorption increases with time of suction. The high rate of water absorption at the early periods of the test has corresponding capillary coefficient of steep slope within the same period. The relationship between the variables $\mathrm{Q}$ the water absorption per unit area of the specimen and $\mathrm{K}$ the capillary coefficient, is that as the water absorption gets higher, so does the capillary coefficient and the percentage of the variation is expressed by the correlation coefficient $R^{2}$. Therefore, the values of $R^{2}$ as depicted in the graphs shows a high percentage of variation. The moisture capacity is $6.9 \%$. All the laboratory tests were, conducted in accordance with standard codes of practice. The significance of the research is that innovative technology is employed to modify and improve processes in construction industry, thus, enhancing sustainable environmental, management of industrial waste, and cheaper and economic construction. With the 30\% replacement of coarse aggregate, the density and water absorption properties of concrete produced are within acceptable limits. Therefore, EPS can be used to produce lightweight concrete that will perform the required function at this level of replacement.
\end{abstract}




\section{Keywords}

Properties, Expanded Polystyrene, Sanded Concrete, Density, Water Absorption

\section{Introduction}

The continuous use of natural materials in construction especially in the production of concrete is having a devastating effect on bio-diversity and the ecosystem. It is because of the environmental consequences of the continuous exploitation of this natural resource that the professionals in the construction industries and built environment have always emphasized on the need to employ alternative materials in place of cement and aggregates. The idea of using alternative materials in replacing some of the natural materials in concrete production especially industrial agricultural and domestic wastes can continue to preserve our natural environment. The continuous exploitation of our natural environment in search of construction materials has adversely affected our environment such as pollution, and depletion of ozone layer through release of gases, etc.

The environmental impacts of the construction industry can be minimized through using waste and recycled materials to replace natural resources [1].

In this research, expanded polystyrene (EPS) was introduced as a partial replacement of coarse aggregate to produce a lightweight concrete, which is expected to be economical, serviceable and meet the required standards for lightweight concretes. In this case, $30 \%$ by volume of natural coarse aggregate is replaced with EPS. Laboratory experiments were conducted on the qualities of concrete produced with this material as lightweight aggregate based on accepted standard codes of practice for concrete.

This work evaluated the mechanical properties in terms of density; and an evaluation of the absorption property using water absorption (capillary absorption and total immersion) as measures. Modeling of parameters using appropriate statistical/mathematical expressions was considered in order to predict and obtain necessary information for the appreciation of the use of this material.

This research work is limited to replacing only about $30 \%$ volume of natural coarse aggregate by equivalent volume of expanded polystyrene (EPS) to test for the density, and water absorption potentials. The essence of choosing $30 \%$ volume as replacement is to ease the control of the mix consistency and bonding because the more the volume of the polystyrene is, the more difficult the cohesion of the concrete ingredients especially with manual batching is.

Concrete is a widely used material the best in the construction industries, which made it to be very popular and versatile. Concrete is a composite inert material comprising of a binder course such as cement, mineral filler (body) or aggregates categorized as, fine (sand) and coarse (gravel or crush stone) aggregates and water [2]. Generally, concrete is classified as dense and lightweight. Lightweight concrete can be described as those weighing less than $1920 \mathrm{~kg} / \mathrm{m}^{3}$. 
Lightweight concrete includes aerated, lightweight aggregates and non-fines concretes; while dense concrete is the popular types for reinforced concrete works with average density of about $2400 \mathrm{~kg} / \mathrm{m}^{3}$ [3]. Concrete is a very variable material having wide range of strengths and stress-strain curves, it is any product or mass made by the use of cementing medium, and it is a composite material [4]. It is therefore possible to say that concrete comprise of mixing cement, aggregates, and often admixtures in appropriate proportions in the present of water; the mixture which undergo chemical reaction forming a paste, on allowed to cure become solid stone like substance. The compositions are natural materials usually extracted from the immediate environment. One of the most important properties of a good quality concrete is low water absorption [5].

It is important to note that one of the transport mechanisms of water into concrete is through the action of capillary absorption and water which flow against gravity is transported spontaneously through the pores or voids of the concrete constituents.

Absorption is the process by which concrete takes in a liquid such as water or aqueous solution by capillary action; and the rate at which water enters the concrete is called absorptivity (or sorptivity) which depends on the size and interconnection of the capillary pores in concrete, and the moisture gradient existing from the surface [6]. Capillary water absorption of concrete is the phenomenon by which water is absorbed into concrete by capillary action and that the fineness of the capillary pores in concrete causes absorption of water by capillary action, as such, a measure of the rate of absorption provides a valuable image of the pore structure of concrete. Capillary action is a more suitable test on water penetration to express the quality of concrete for structures aboveground such as building [7].

Density of concrete is one of the important parameters in structural behavior, and the density of concrete is a measure of its weight [8]. The higher the density of concrete the more is the dead load on structure. Most lightweight aggregate concrete used in structure, have equilibrium densities between $1760-1840 \mathrm{~kg} / \mathrm{m}^{3}$ [9]. However, according to [10] [11] they have density range of $300 \mathrm{~kg} / \mathrm{m}^{3}$ up to $1840 \mathrm{~kg} / \mathrm{m}^{3}$, with dry density not exceeding $1840 \mathrm{~kg} / \mathrm{m}^{3}$

Polystyrene is widely used as packaging materials in both large and medium industries and their post-consumer disposal/management post many problems. Expanded polystyrene is non-biodegradable thus constitute disposal problem, as such an environmental nuisance. Expanded polystyrene concrete has scope for nonstructural applications, like wall panels, partition walls, etc. [12]. Polystyrene wastes are becoming a major environmental concern due to the large quantities that are produced and the fact that they are not biodegradable. The development of concrete with non-conventional aggregates, such as polystyrene foam waste has been considered to improve the properties of the concrete, to lower costs, and to recycle polymeric materials [13]. Innovative technology utilizing industrial base waste is a way of modification and improvement in construction. 
The use of high amount of EPS in concrete here means a high valuable waste disposal method, which provides solution for environmental problems and polymetric material is recycled. The high percentage of coarse aggregate replacement with EPS (i.e. 30\%) means a high reduction in the dead load (self-weight) of the concrete elements, improvement of the properties of concrete and low costs, which translates to cheap and economic construction. This is an innovative technology using industrial based waste in a way of modification and improvement in construction.

\section{Materials and Methods}

\subsection{Materials}

The materials for this research experiments were locally sourced from the immediate environment in Kaura-Namoda, Zamfara state.

Dangote brand of ordinary Portland cement (OPC) of grade 42.5R conforming to BS and ASTM standards commonly used in concrete, free from hard lumps and of uniform colour with medium rate of hardening used as the binder was bought from local cement market in kaura Namoda.

The coarse aggregate (natural stone) was obtained from a nearby local aggregate site along Kaura Namoda/Zurmi local government in zamfara state. The maximum size of coarse aggregate for this experiment was $19 \mathrm{~mm}$. The fine aggregate (sharp sand) was obtained from river Gagale in Kaura Namoda.

The Water used for the mixture and curing of concrete in the experiment is potable water from drinking water tap confirmed to be free from impurities/injurious amount of deleterious materials that can lead to concrete distress.

Expanded polystyrene (EPS) is obtained as waste from packaging container of workshops and laboratory equipment supplied to the Federal polytechnic, Kaura Namoda. The EPS was manually broken into approximately equal sizes of the natural coarse aggregate.

\subsection{Batching and Mixing}

The mix proportion which was obtained from the trail mix of water/cement ratio for the experiments was (1:2:4) by weight with a water/cement ratio of $0.5 \%$. In this research, only $30 \%$ of the volume of the coarse aggregate was replaced by equivalent volume of EPS and mixing was manually done in the laboratory. The curing of concrete cubes was by total submerging inside water in a curing tank. The material mix proportion is as shown in Table 1.

\section{Experimental Methods}

\subsection{Sieve Analysis}

The sieve analysis for the aggregates was conducted to determine their particle size distribution using recommended standard sieve according to [14]. The fineness modulus of the fine and coarse aggregates as material proerties, were 
determined from the test as shown in Table 2.

\subsection{Total Water Absorption}

The experimental process is the same as that of capillary absorption except that; in this case, the cubes are totally submerged in water inside a container. The level of water above the face of concrete in the container is kept at nearly $50 \mathrm{~mm}$. Increase in sample mass as water absorbed was measured by weighing each sample at prescribed time intervals of $1,3,5,15,30 \mathrm{~min}, 1,4,24$, and 48, and the average of each set of two sample mass was computed as shown in Table 3.

Total mass of water absorbed at each time was obtained by subtracting the dry weight from the wet.

\subsection{Capillary Water Absorption}

Concrete specimens of $150 \times 150 \times 150 \mathrm{~mm}$ were casted from the mix. For the curing ages of 7 and 28 days, two specimens were produced and after 24 hours, they were demoulded and placed in water for curing under the same condition as those cubes for compression test until the required testing days.

The samples were, dried in an oven at $85^{\circ} \mathrm{C}$ and at regular intervals removed and weighed to ensure constant dry weight before commencing the test and the maximum dry period was $72 \mathrm{hrs}$. The specimens were then, left to cool at normal room temperature in the laboratory before the water absorption test commenced. The capillary water absorption test was conducted by placing one face of each sample just in contact with water on supports in a shallow capillary tray and water was gradually added until the level rose above the contact surface by

Table 1. Concrete mix proportions for the experiment.

\begin{tabular}{ccccccc}
\hline Ref. & w/c ratio & Water $(\mathrm{kg})$ & Cement $(\mathrm{kg})$ & Fine sand $(\mathrm{kg})$ & Coarse Aggt. $(\mathrm{kg})$ & EPS \\
\hline Values & 0.5 & 12.5 & 25 & 50 & 100 & $30 \%$ \\
\hline
\end{tabular}

Table 2. Material properties.

\begin{tabular}{ccc}
\hline Characteristics & Coarse aggregate & Sand aggregate \\
\hline Max. Size $(\mathrm{mm})$ & 20 & Retained in $4.75 \mathrm{~mm}$ sieve \\
Bulk density $\left(\mathrm{kg} / \mathrm{m}^{3}\right)$ & 1523 & 1410 \\
Water absorption \% & 2.3 & 5.2 \\
Fineness modulus & 1.42 & 2.67 \\
\hline
\end{tabular}

Table 3. Total Absorption.

\begin{tabular}{cccccccccccc}
\hline & \multicolumn{3}{c}{ Inertial wts. } & \multicolumn{6}{c}{ Time interval of weighing/individual specimen weights (gm.) } \\
\cline { 2 - 11 } & Wet & oven & $1 \mathrm{~min}$ & $3 \mathrm{~min}$ & $5 \mathrm{~min}$ & $15 \mathrm{~min}$ & $30 \mathrm{~min}$ & $1 \mathrm{hr}$ & $4 \mathrm{hr}$ & $24 \mathrm{hr}$ & $48 \mathrm{hr}$ \\
\hline $\mathrm{C}_{1}$ & 5396 & 5030 & 65 & 90 & 105 & 135 & 180 & 210 & 290 & 355 & 360 \\
$\mathrm{C}_{2}$ & 6389 & 5930 & 55 & 65 & 85 & 110 & 150 & 195 & 310 & 405 & 400 \\
\hline
\end{tabular}


about $(2-3) \mathrm{mm}$ as depicted in Figure 1.

Increase in sample mass as water absorbed was measured by weighing each sample at prescribed time intervals of 1,3, 5, 15, $30 \mathrm{~min}, 1,4,24$, and 48, and the average of each set of two sample mass was computed as shown in Table 4. Total mass of water absorbed at each time, was obtained by subtracting the dry weight from the wet. The capillary water absorption was computed by the ratio of mass gained to the area of specimen in contact with water in $\left(\mathrm{g} / \mathrm{mm}^{2}\right)$ which was plotted against the square root of time, the initial slope of which was considered as water absorption coefficient. The area of concrete in contact with water is $150 \mathrm{~mm}$ $\times 150 \mathrm{~mm}=22,500 \mathrm{~mm}^{2}$. Capillary water absorption coefficient is the slope of linear variation of absorbed water per unit area plotted against square root of time for the experiment.

\subsection{Absorption Capacity (Moisture Content)}

The absorption capacity is determined from the wet weight of cubes and their corresponding oven dry weights at specified period. If the initial wet weight is $A$, and the oven dried weight is $B$, the absorption capacity is then computed in percentage as;

$$
\mathrm{MC}(\%)=\frac{A-B}{B} \times 100 \%
$$

All the water absorption tests were, conducted in accordance with [15].

\subsection{Density}

Both the wet and dry densities of concrete cubes $(150 \times 150 \times 150)$ size were performed.

Density,

$$
\rho=\frac{\text { mass }}{\text { volume }}
$$

Wet density,

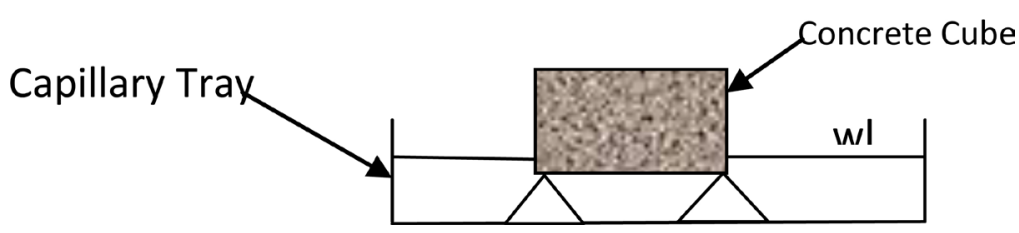

Figure 1. Sample of capillary water test illustration.

Table 4. Capillary absorption.

\begin{tabular}{ccccccccccccc}
\hline \multirow{3}{*}{ Mark } & \multicolumn{1}{c}{ Inertial wts. } & \multicolumn{7}{c}{ Time interval of weighing/individual specimen weights (gm.) } \\
\cline { 2 - 10 } & Wet & oven & 1 min & 3 min & 5 min & 15 min & 30 min & $1 \mathrm{hr}$ & $4 \mathrm{hr}$ & $24 \mathrm{hr}$ & $48 \mathrm{hr}$ \\
\hline$B_{1}$ & 5391 & 5025 & 15 & 20 & 25 & 40 & 55 & 75 & 135 & 250 & 290 \\
$B_{2}$ & 6988 & 6615 & 20 & 25 & 30 & 40 & 50 & 65 & 110 & 200 & 235 \\
\hline
\end{tabular}




$$
\rho_{b}=\frac{\text { wet mass }}{\text { volume }}
$$

Dry density,

$$
\rho_{d}=\frac{\text { oven dry weight }}{\text { volume }}
$$

The density test was conducted in accordance with [16] specifications.

\section{Results and Discussion}

The result of EPS concrete water absorption at 28 days of curing is presented in Table 5 and Figure 2 and Figure 3. These figures also showed that total water and capillary water absorption increases with time of suction. The modeled relationship between the capillary absorption and square root of time showed strong polynomial correlation with high regression value of 0.9997 (99.9\%). While the modeled relationship between the capillary water gain and total water gain with time showed strong polynomial and logarithm relationship with regression value of $0.9556(95.5 \%)$ and $0.9733(97.33 \%)$ respectively. These from the graphs, shows that the high rate of water absorption at the early periods of the test has corresponding capillary coefficient of steep slope within the same period. The relationship between the variables $Q$ the water absorption per unit area of the specimen and $\mathrm{K}$ the capillary coefficient, is that as the water absorption gets

Table 5. Capillary Water absorption after 28 days of curing.

\begin{tabular}{cccccccccc}
\hline & \multicolumn{1}{c}{ Time (t) in minutes } \\
\cline { 2 - 11 } Absorptions & 1 & 3 & 5 & 15 & 30 & 60 & 240 & 1440 & 2880 \\
\hline Total water gain $(\mathrm{gm})$ & 60.0 & 77.5 & 95.0 & 122.5 & 165.0 & 202.5 & 300.0 & 380.0 & 380.0 \\
Capillary water gain $(\mathrm{gm})$ & 17.5 & 22.5 & 27.5 & 40.0 & 52.5 & 70.0 & 122.5 & 225 & 262.5 \\
Capillary Absorpt $\left(\mathrm{g} / \mathrm{mm}^{2}\right)$ & 0.00078 & 0.001 & 0.0012 & 0.0018 & 0.0023 & 0.0031 & 0.0054 & 0.01 & 0.012 \\
$\sqrt{t}$ & 1 & 1.73 & 2.23 & 3.87 & 5.47 & 7.74 & 15.49 & 37.94 & 53.66 \\
\hline
\end{tabular}

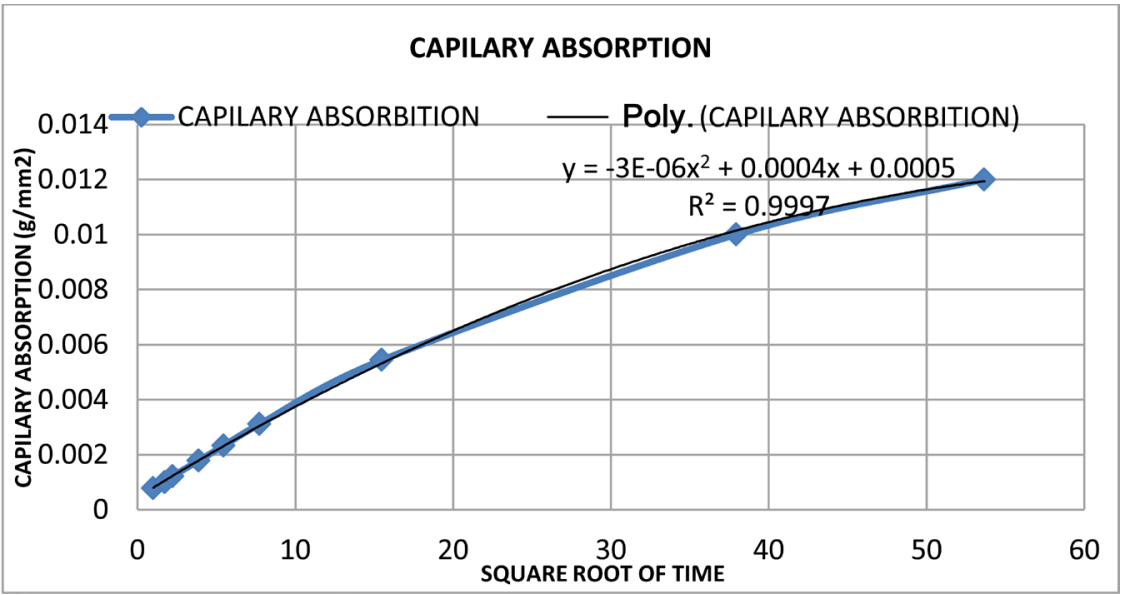

Figure 2. Capillary absorption vs $\sqrt{t}$. 


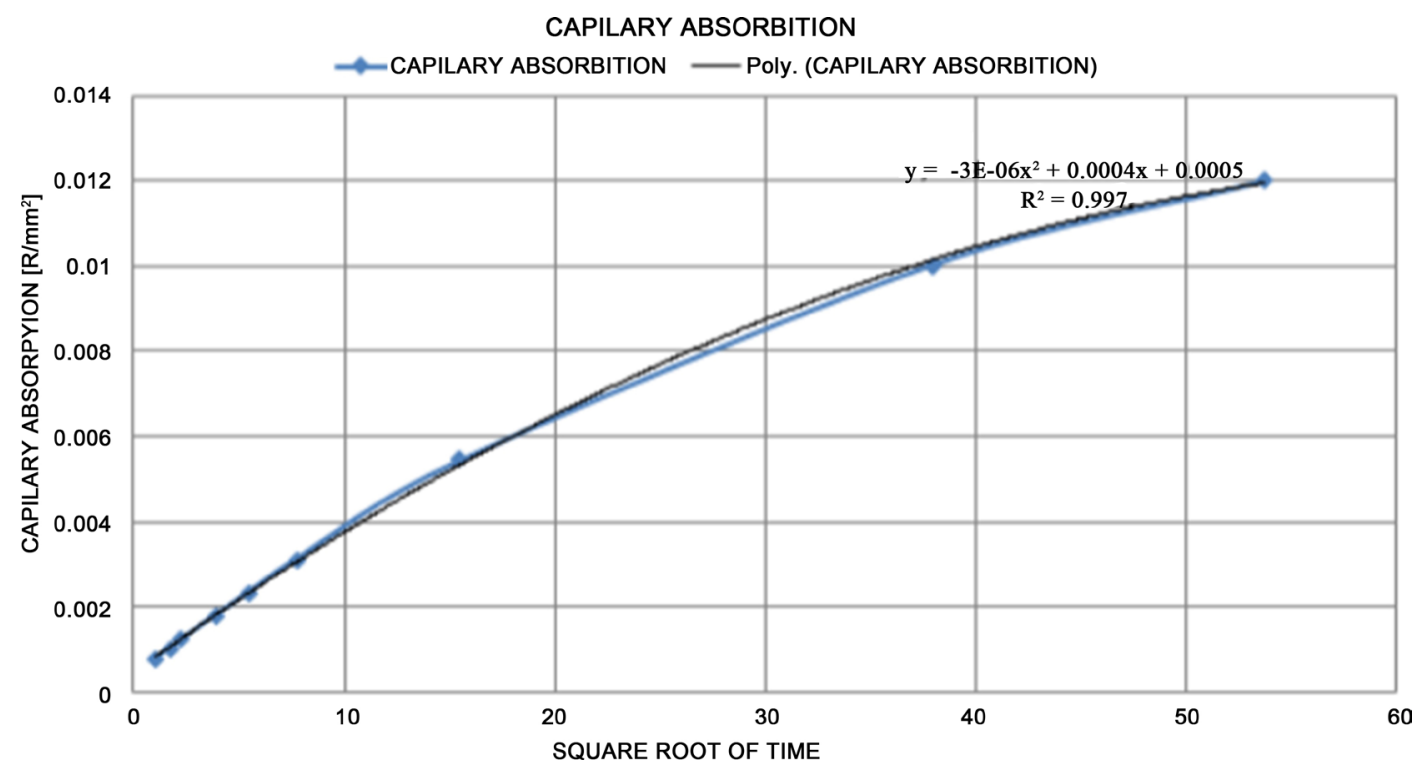

Figure 3. Water gain vs Time $(t)$.

higher, so does the capillary coefficient and the percentage of the variation is expressed by the correlation coeffient $R^{2}$. Therefore, the values of $R^{2}$ as depicted in the graphs shows a high percentage of variation.

Average initial wet weight of cubes $A=6041 \mathrm{~g}$ and average oven dry weight of cubes $B=5650 \mathrm{~g}$.

$$
\text { Moisture capacity } \mathrm{MC}=\frac{6041-5650}{5650} \times 100=6.9 \%
$$

The values for bulk and oven dry densities are computed using Equations (2) and (3) respectively and the results was found to be $1789 \mathrm{~kg} / \mathrm{m}^{3}$ and $1674 \mathrm{~kg} / \mathrm{m}^{3}$ for the bulk and oven dry density respectively. This is within the range for lightweight concrete as specified by [8] [9]. However, this result shows that the density of EPS modified concrete is less than the density of normal aggregate concrete.

\section{Conclusion and Recommendations}

\subsection{Conclusions}

The capillary absorption and square root of time showed a strong polynomial relationship with high regression while the capillary water gain and total water gain with time showed strong polynomial and logarithm relationship with high regression value.

The values for bulk density and dry density are found to be $1789 \mathrm{~kg} / \mathrm{m}^{3}$ and $1674 \mathrm{~kg} / \mathrm{m}^{3}$ respectively and this is within the acceptable range for lightweight concrete. The moisture absorption capacity of the EPS concrete was measured to be $6.9 \%$.

\subsection{Recommendations}

It can be used to solve problems of weight, density, durability, and size structural 
elements. Further studies in this area will be of important to add more values to the use of this material in concrete production and waste management.

\section{Conflicts of Interest}

The authors declare no conflicts of interest regarding the publication of this paper.

\section{References}

[1] Herki, B.M.A. (2017) Combined Effects of Densified Polystyrene and Unprocessed Fly Ash on Concrete Engineering Properties. Buildings. http://www.mdpi.com/buildings

[2] Oyenuga, V.O. (2001) Reinforced Concrete Design. 2nd Edition, Asros Ltd., Lagos.

[3] Neville, A.M. and Brooks, J.J. (2010) Concrete Technology. 2nd Edition, Pearson Education Ltd., London.

[4] Mosley, W.H., Bungey J.H. and Husle, R. (2007) Reinforced Concrete Design. 6th Edition, Palgrave Publishers Ltd., New York.

[5] Herki, B.M.A. (2017) Absorption Characteristics of Lightweight Concrete Containing Densified Polystyrene. Civil Engineering Journal, 3.

[6] Neil, J. and Dhir, R.K. (1996) Civil Engineering Materials. 5th Edition, Macmillan Education, Basingstoke.

[7] Khatib, J.M. and Clay, R.M. (2003) Absorption Characteristics of Metakaolin Concrete. Cement and Concrete Research.

[8] Mulla, A. and Shelake, A. (2016) Lightweight Expanded Polystyrene Beads Concrete. International Journal of Research in Advent Technology, E-ISSN: 2321-9637 Special Issue National Conference "VishwaCon'16", 17-21.

[9] Joseph, F.L. and James, H.P. (2006) Significance of Tests and Properties of Concrete $\&$ Concrete-Making Materials. ASTM International, West Conshohocken.

[10] Hjh, K.M.I., Mohamad, S.F. and Norpadzlihatun, bte. M. (2010) Study of Lightweight Concrete Behavior.

[11] Kenneth, S. and Harmon, P.E. (2006) Engineering Properties of Structural Lightweight Concrete. Carolina Stalite Company, Salisbury.

[12] Mandlik, A., Sood, T.S., Karade, S., Naik, S. and Kulkarni, A. (2013) Lightweight Concrete Using EPS. ISSN (Online): 2319-7064, International Journal of Science and Research (IJSR), 4, 2007-2010.

[13] Mustafa Al Bakri, A.M., Zarina, Y., Norazian, M.N., Kamarudin, H., Ruzaidi, C.M. and Rafiza, A.R. (2013) Study of Concrete using Modified Polystyrene Coarse Aggregate. Advanced Materials Research, 740, 502-506. https://doi.org/10.4028/www.scientific.net/AMR.740.502

[14] British Standards Institution (2012) Testing for Geometric Properties of Aggregates Part 1: Determination of Particle Size Distribution-Sieve Method. BS EN 933-1.

[15] British Standards Institution (2011) Testing Concrete: Method for Determination of Water Absorption. BS1881-122.

[16] British Standards Institution (2009) Testing Hardened Concrete Part 7: Density of Hardened Concrete. BS EN 12390-7. 